\title{
Direct Laser Synthesis of Ag Nanoparticles from Ammonia-alcoholic Solutions of $\mathrm{AgNO}_{3}$
}

\author{
Mikhail Dmitrievich Mikhailov, ${ }^{1}$ Ilya Evgeńevich Kolesnikov ${ }^{2}$ \\ and Alina Anvyarovna Manshina ${ }^{2}$ ** \\ ${ }^{1}$ Scientific and Technological Institute of Optical Material Science, 192171, Babushkina, 36A, St. Petersburg, Russia \\ ${ }^{2}$ Saint Petersburg State University, 199034, Universitetskaya nab., 7-9, St. Petersburg, Russia \\ * Corresponding author: E-mail: a.manshina@spbu.ru \\ Tel. +781242843 35, fax. +78124287479
}

Received: 04-08-2016

\begin{abstract}
$\mathrm{Ag}$ nanoparticles were synthesized as a result of irradiation of ammonia-alcoholic solution of $\mathrm{AgNO}_{3}$ with focused beam of Nd:YAG laser. The synthesized nanoparticles were characterized with SEM and EDX analysis, dynamic light scattering technique, absorption and luminescence spectroscopies. The average size of synthesized nanoparticles which is from 25 to $100 \mathrm{~nm}$ demonstrates a linear dependence on molar concentration of the used solution. Optical and luminescence properties of obtained Ag nanoparticles were demonstrated.
\end{abstract}

Keywords: direct laser synthesis, nanoparticles, Ag, surface plasmon resonance

\section{Introduction}

Lately, a lot of attention is given to the development of new methods of synthesis of noble metals' nanoparticles (NPs). Special interest to such NPs is connected with their unique properties that are especially important for application in biology, medicine, ecology etc. ${ }^{1-4}$ Optical properties of metallic nanostructures are mostly defined by plasmons, which are a quantum of plasma oscillation. When the frequencies of external electromagnetic radiation and of localized surface plasmon coincide, the resonance appears which leads to the strengthening of the field on the structure surface and increase of the absorption section, which in its turn can be used in different spheres of science and technology. Ag NPs have the most intensive plasmon absorption, ${ }^{5}$ can be promising as a disinfecting addition in form of NPs' colloidal solutions, ${ }^{6-8}$ can be used for the long-term control of the processes in cells of live organisms or as biomarkers in cancer diagnosis methods. ${ }^{9}$

Chemical methods of NPs' synthesis (especially metallic ones) are well-known, ${ }^{10-12}$ but, apart from NPs obtained as a result of reduction reactions or ion exchange, there are always by-products present, which confines the use of these methods. That is why lately in the last 10 years new alternative ways of getting metal NPs are being developed, in particular with the use of laser irradiation. One of these methods is the direct synthesis of noble metals' NPs (Au, Ag, Pt) from metal salts' solutions.

The method was first realized a few years ago and is still presented in a few works. ${ }^{13,14}$ The idea is to initiate the chemical reaction by focusing laser beam in a solution, and to get NPs as one of the products. Direction and high intensity of laser beam, as well as the possibility to use pulsed laser radiation, secure spatial-temporal limitation of the chemical reaction (localization of the chemical process of NPs' formation). So, the laser focus volume can be considered as a chemical micro reactor restricting amount of the reacting substance. The time-defining parameter is the pulse duration. Another intriguing feature of the laser-induced synthesis in the case of high-intense laser radiation $10^{12}-10^{18} \mathrm{~W} / \mathrm{cm}^{2}$ is realization of the chemical reaction at extremely non-equilibrium thermodynamic state that is potential for specific routs and products of the reaction.

In spite of intense research of chemical processes under laser irradiation, there have only been published papers describing the possibility of process realization in limited quantity of solutions. By the start of this work we 
managed to find an example of realization of the direct laser synthesis method for obtaining Ag NPs only from water solutions of $\mathrm{AgNO}_{3} \cdot{ }^{15}$ That is why the aim of our work is the broadening solutions compositions for direct laser synthesis of Ag NPs.

\section{Experimental}

Solutions' compositions used in this work were chosen taking into consideration that the used compounds should make a homogeneous solution (that is, to be well dissolvable), and a presupposed possibility of laser beam initiated chemical reactions that lead to Ag NPs formation. As a result, there were chosen 3 possible solutions: ammonia-alcoholic solution of $\mathrm{AgNO}_{3}$, water solution of $\mathrm{AgC}_{2} \mathrm{H}_{3} \mathrm{O}_{2}$ and $\mathrm{AgNO}_{3}$ solution in a water urea solution. To make the research fuller, 4 different concentrations of each solution were prepared. The use of low-concentrated solution did not allow obtaining enough reaction products for further research; the other limitation is high-concentrated solutions close to saturation that result in salts precipitation. That is why in each of the used solutions the salts concentrations were optimized. For ammonia-alcoholic solutions concentration is $0.1 \mathrm{M}, 0.2 \mathrm{M}, 0.3 \mathrm{M}, 0.44$ $\mathrm{M}$ of $\mathrm{AgNO}_{3}$, ratio $\mathrm{NH}_{4} \mathrm{OH}: \mathrm{C}_{2} \mathrm{H}_{5} \mathrm{OH}$ is 1:2. For $\mathrm{Ag}$ $\mathrm{C}_{2} \mathrm{H}_{3} \mathrm{O}_{2}$ and $\mathrm{AgNO}_{3}$ in urea: $0.035 \mathrm{M}, 0.07 \mathrm{M}, 0.105 \mathrm{M}$, 0.14 M. 1-2 drops of oleic acid was added to each solution as a stabilizer. ${ }^{16,17}$. The solutions were prepared by weight method using chemically pure chemicals. One may see the process of laser synthesis in Fig. 1a.

$3 \mathrm{ml}$ of the solution was put in a standard $1 \mathrm{~cm} \mathrm{cu}-$ vette. Laser irradiation was directed into the cuvette from above using mirror (reflectivity $\mathrm{R}>99.0 \%$ ) and focused into the solution volume (focal length $\mathrm{f}=5 \mathrm{~cm}$ ). For NPs synthesis $\mathrm{Nd}$ :YAG laser was used $(\lambda=1064 \mathrm{~nm}, \tau=5 \mathrm{~ns}$, $v=50 \mathrm{~Hz}$, pulse energy $-100 \mathrm{~mJ}$ ). Optical breakdown (height about $100 \mu \mathrm{m}$ ) was observed only in focal volume inside the solution. Duration of laser irradiation of the salts solution for 10 minutes was found to be enough for pronounced colorification and opacification of the solution that can be considered as an indirect evidence of a chemical reaction (Fig. 1b). Coloring depended upon the composition and concentration of the solution, and in case of ammonia-alcoholic solutions the color change was especially noticeable. It should be noted that solution was in static condition during laser irradiation.

Scanning electron micrograph (SEM) images of Ag NPs were made using SUPRA 40VP WDS scanning electron microscope with the accelerating voltage $2-5 \mathrm{kV}$ and resolution of $4 \mathrm{~nm}$. The size of synthesized particles was measured with laser diffraction particle size analyzer Nanopartica SZ100 (Horiba Jobin Yvon). Absorption spectra were obtained with Lambda 1050 (Perkin Elmer) double beam absorption spectrometer. The emission spectra of nanoparticles were measured with fluorescence spectrometer Lumina (Thermo Fisher Scientific), with excitation wavelength $270 \mathrm{~nm}$, the object of analysis was the solution obtained directly during the synthesis.

\section{Results and Discussion}

Microphotographs of the particles obtained as a result of laser irradiation of ammonia-alcoholic solutions of $\mathrm{AgNO}_{3}$ of different concentration are presented in Fig. 2. Distribution of NP's size was obtained using dynamic light scattering technique (Inset of Fig. 2). One may see that the size of the particles is changing from 25 to $100 \mathrm{~nm}$ and depends on concentration of the used solution; both separate Ag NPs and their agglomerations present in the solutions, but number of observed agglomerates is small.

As for size of the synthesized NPs, it was found to be linearly increased with solution concentration (0.1-0.4 M) with symbate size distribution growth (Fig. 3a). One should note that the revealed linear dependence can be used to get Ag NPs of prescribed size, which is utterly important for further use of the obtained NPs. In accordance with EDX analysis the obtained NPs consist of silver (Fig.
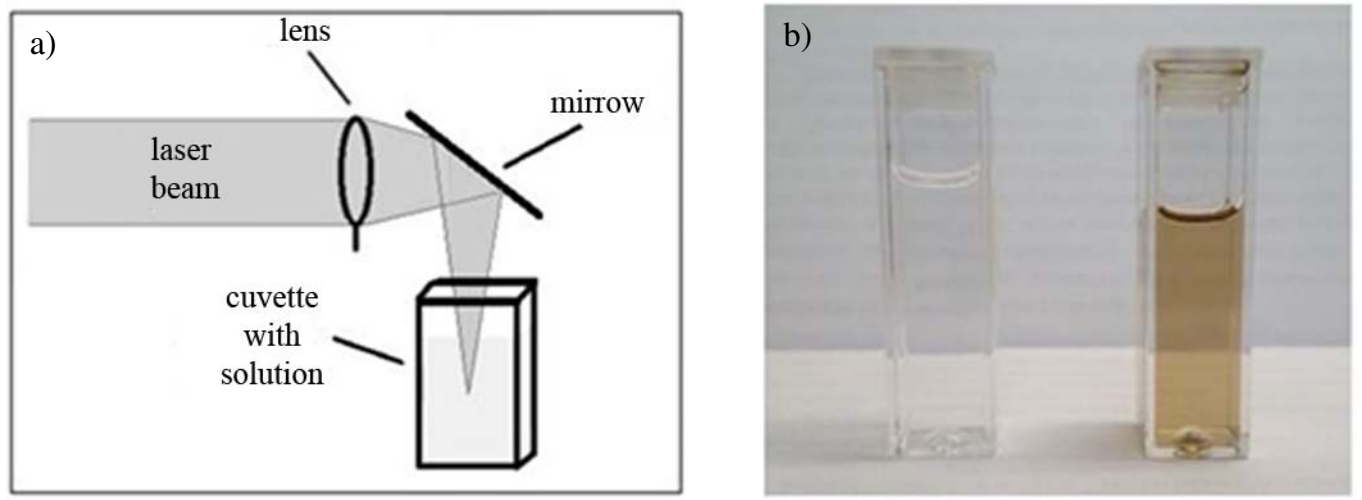

Fig. 1. a) Scheme of direct laser synthesis; b) ammonia-alcoholic solution before (on the left) and after (on the right) laser irradiation 

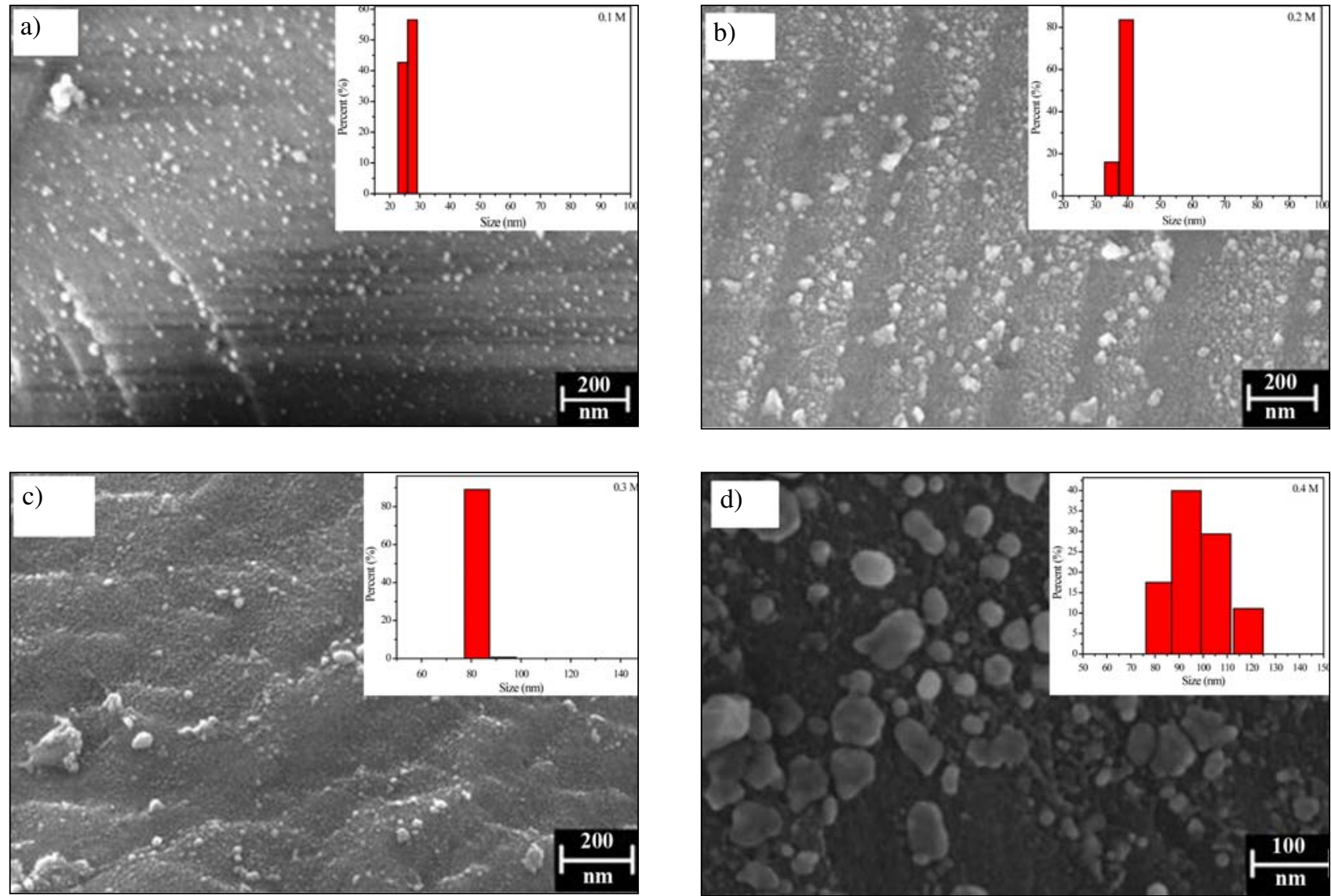

Fig. 2. Microphotographs of the particles obtained from ammonia-alcoholic solutions of different concentration: a) $0.1 \mathrm{M}$, b) $0.2 \mathrm{M}$, c) $0.3 \mathrm{M}$, d) 0.4 M. Size distribution obtained with dynamic light scattering is presented in inset

a)

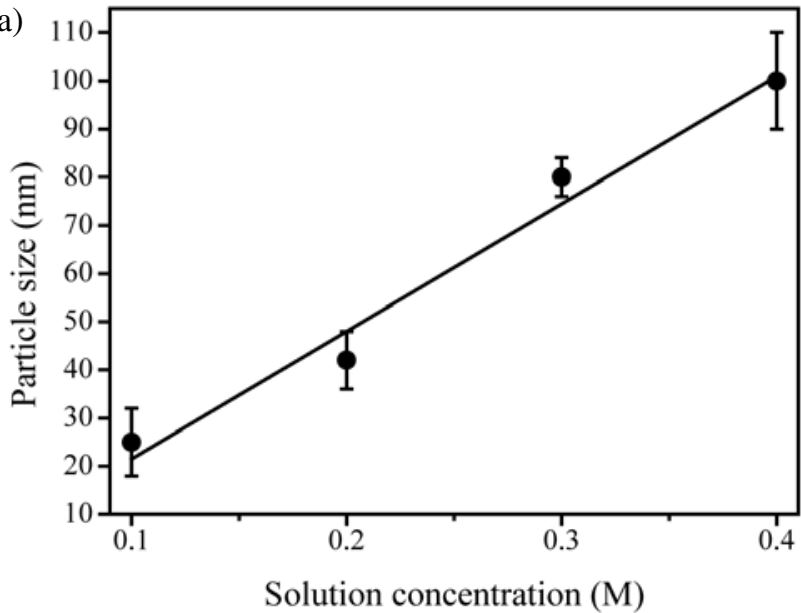

b)

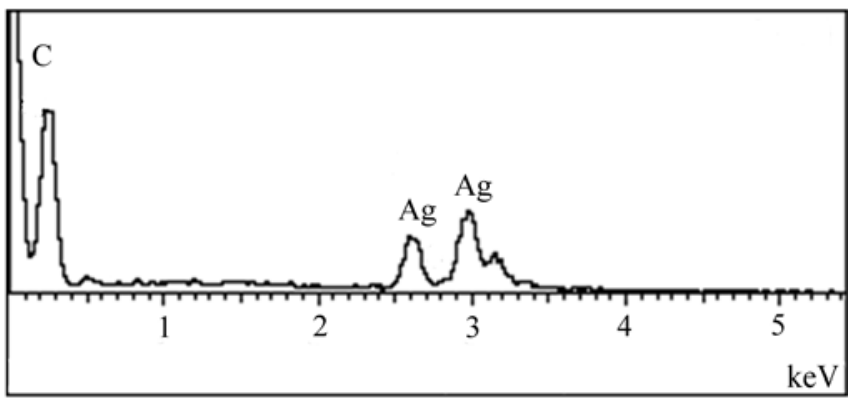

Fig. 3. a) Dependence of the Ag NPs' average size on the concentration of the used ammonia-alcoholic solution, b) EDX-spectrum of NPs obtained from ammonia-alcoholic solutions

3b). As for solutions of other compositions (water solution of $\mathrm{AgC}_{2} \mathrm{H}_{3} \mathrm{O}_{2}$ and $\mathrm{AgNO}_{3}$ solution in a water urea solution) the formation of Ag NPs was not confirmed with SEM and EDX analyses.
Formation of Ag NPs under exposure to laser radiation can be a product of redox chemical reaction that is thermally initiated as a result of laser irradiation of ammonia-alcoholic solutions. 


$$
\begin{aligned}
& {\left[\mathrm{Ag}\left(\mathrm{NH}_{3}\right)_{2}\right]^{+}+\mathrm{e}=\mathrm{Ag}^{\circ} \downarrow+2 \mathrm{NH}_{3}} \\
& \mathrm{CH}_{3} \mathrm{CH}_{2} \mathrm{OH}-2 \mathrm{e}+2 \mathrm{OH}^{-}=\mathrm{CH}_{3} \mathrm{COOH}+\mathrm{H}_{2} \mathrm{O}
\end{aligned}
$$

Numerical estimations show that during the laser irradiation the efficient heating is reached in the area, the dimension of which does not exceed the focal volume: about $10 \mu \mathrm{m}$ in diameter and $100 \mu \mathrm{m}$ long. Focal volume was estimated using simple formulae $\Delta l=f \theta$ and $\Delta z=\frac{f^{2} \theta}{D}$ (f is focal length, $\theta$ is beam divergence, $\mathrm{D}$ is diameter of laser beam) taking into account non-Gaussian energy distribution in laser beam. As for temporal localization of the chemical reaction, the low pulse repetition rate $-50 \mathrm{~Hz}$ gives the time interval between successive la- ser pulses much longer than the $\mu$ s timescale for diffusion of heat out of the focal volume, so the next pulse arrives when the temperature drops to the initial temperature. ${ }^{18,19}$ Thus, one can estimate the area of the chemical reaction as equal to $10^{-8} \mathrm{~cm}^{3}$. For the solution concentration $0.1 \mathrm{M}$ the amount of $\mathrm{Ag}$ in the reaction area is enough to create one $200 \mathrm{~nm} \mathrm{NP}$, and the size grows with solution concentration (C) according to $\sqrt[3]{\mathrm{C}}{ }^{20}$ However, the sizes of the experimentally obtained NPs' are much smaller than the estimated ones, although the size growth tendency with concentration growth takes place. The fact can be explained either by reaction incompleteness during the laser pulse or by formation of several crystallization centers in the laser focal volume.

Fig. 4 shows normalized absorption spectra of the ammonia-alcoholic solutions exposed to laser irradiation.
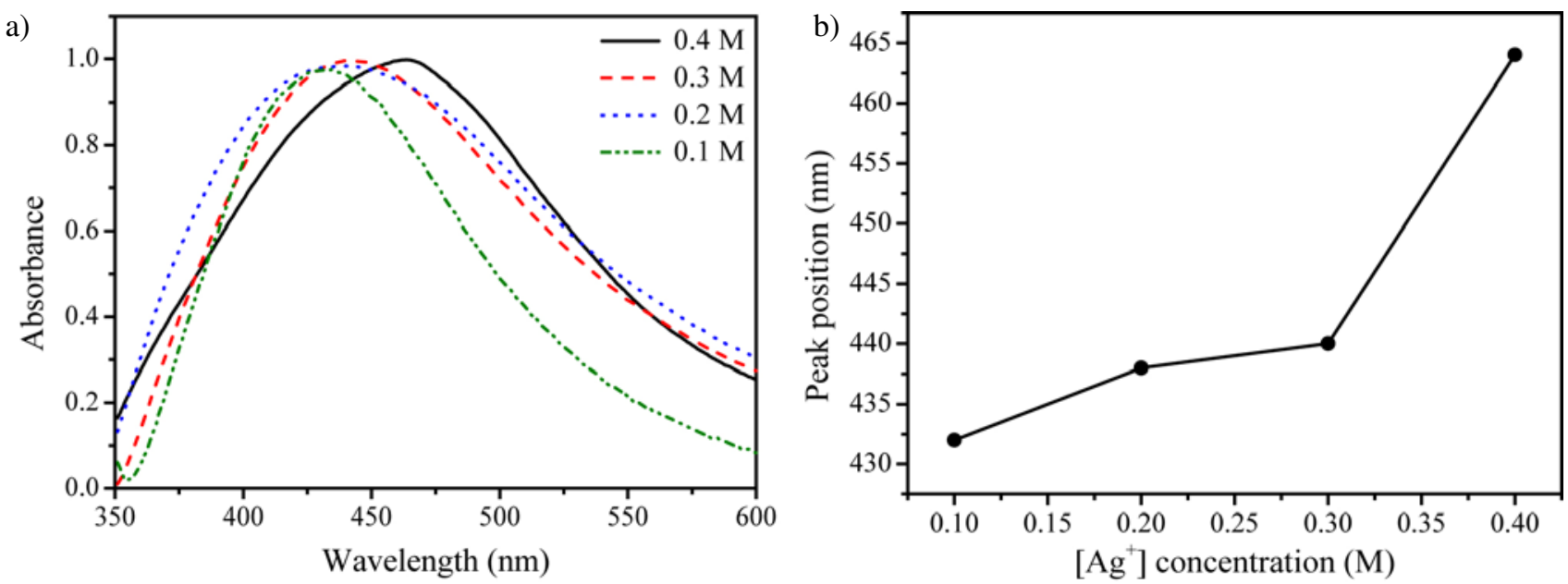

Fig. 4. a) Absorption of ammonia-alcoholic solutions exposed to laser irradiation; b) dependence of the band peak of Ag NPs' SPR upon the solution concentration
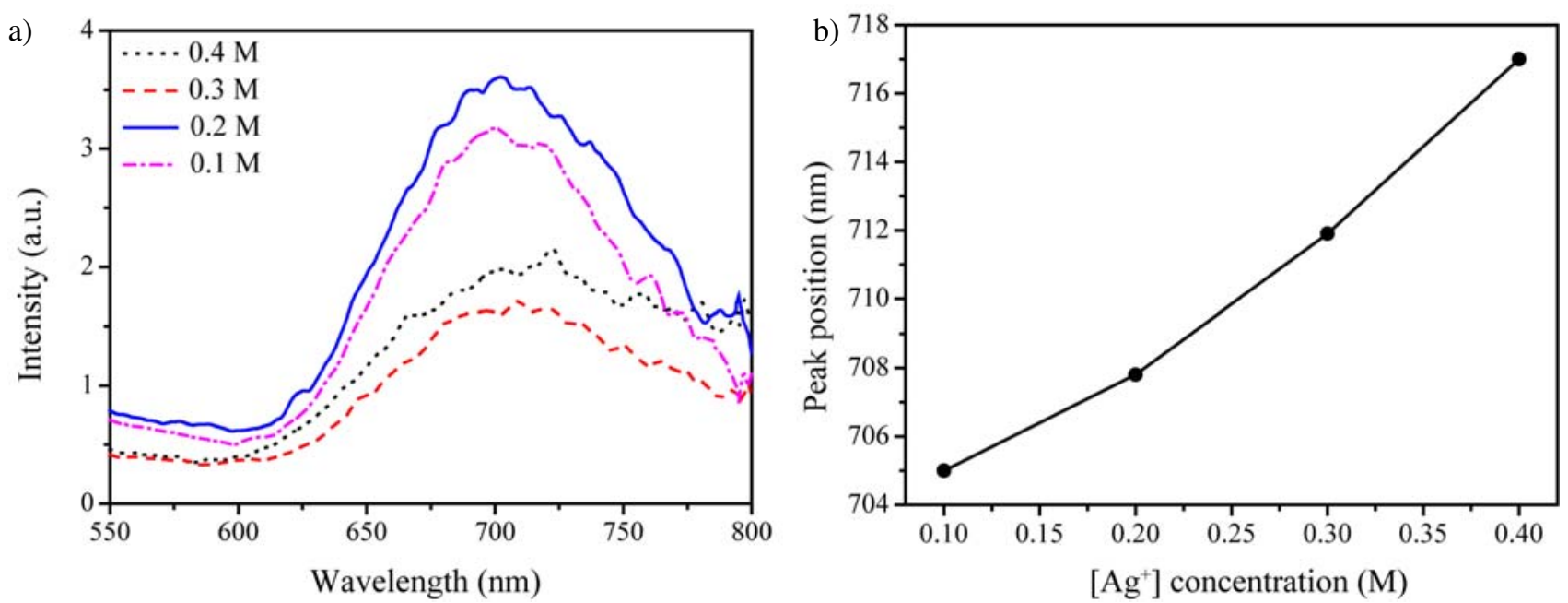

Fig. 5. a) Emission spectra of Ag NPs obtained from ammonia-alcoholic $\mathrm{AgNO}_{3}$ solutions of different concentration; b) dependence of the Ag NPs' luminescence peaks upon the concentration of the used solution 
The characteristic absorption peaks located at the wavelength 420-480 nm correspond to the bands of the surface plasmon resonance (SPR) and confirms the formation of Ag NPs' during the direct laser synthesis. The observed redshift of the SPR line coincides with the NPs' size increase with the solution concentration that is in keeping with the Mie-Drude theory. ${ }^{1,21,22}$

Fig. 5a shows luminescence spectra of the Ag NPs obtained as a result of direct laser synthesis from ammonia-alcoholic solutions with different concentrations of $\mathrm{AgNO}_{3}$, as well as the dependence of the luminescence peak position upon the concentration of the used solution (Fig. 5b). One may see that along with the solution concentration increase, the peaks' position slightly shifts to the long-wave region that is connected with the size increase of Ag NPs. ${ }^{23,24}$ These results coincide with the earlier conclusion about the dependence of NPs' size upon the concentration of the used solution.

\section{Conclusion}

Thus, it was demonstrated the possibility of direct laser synthesis of Ag NPs from ammonia-alcoholic Ag$\mathrm{NO}_{3}$ solutions with various concentrations $0.1-0.4 \mathrm{M}$. The obtained NPs are characterized by high chemical purity, no impurities were observed. It was shown that the size of the NPs demonstrates narrow distribution and can be controllably changed from 25 and $100 \mathrm{~nm}$ by virtue of linear dependence on solution concentration. The plasmonic absorption and luminescence of the synthesized Ag NPs were demonstrated that can be useful for biomedical applications.

\section{Acknowledgements}

The authors thank Yulia Leonova for help with carrying out synthesis procedures. This research has been supported by The Ministry of Education and Science of the Russian Federation (\# 14.604.21.0078, RFMEFI60414X0078). Experimental investigations were carried out in the «Center for Optical and Laser materials research», and «Interdisciplinary Resource Center for Nanotechnology» (Saint Petersburg State University).

\section{References}

1. U. Kreibig, M. Vollmer, Optical Properties of Metal Clusters, Springer Science \& Business Media, 2013.

2. O. V. Salata, J. Nanobiotechnology 2004, 2 (1), 3. https://doi.org/10.1186/1477-3155-2-3

3. K.-S. Lee, M. A. El-Sayed, J. Phys. Chem. B 2006, 110 (39), 19220-19225. https://doi.org/10.1021/jp062536y

4. C. J. Murphy, A. M. Gole, J. W. Stone, P. N. Sisco, A. M. Al- kilany, E. C. Goldsmith, S. C. Baxter, Acc. Chem. Res. 2008, 41 (12), 1721-1730. https://doi.org/10.1021/ar800035u

5. O. Masala, R. Seshadri, Annu. Rev. Mater. Res. 2004, 34, 41-81.

https://doi.org/10.1146/annurev.matsci.34.052803.090949

6. S. Priyadarshini, V. Gopinath, N. M. Priyadharsshini, D.Ali Mubarak, P. Velusamy, Colloids Surfaces B Biointerfaces 2013, 102, 232-237. https://doi.org/10.1016/j.colsurfb.2012.08.018

7. J. R. Morones, J. L. Elechiguerra, A. Camacho, K. Holt, J. B. Kouri, J. T. Ramírez, M. J. Yacaman, Nanotechnology 2005, 16 (10), 2346. https://doi.org/10.1088/0957-4484/16/10/059

8. C.-N. Lok, C.-M. Ho, R. Chen, Q.-Y. He, W.-Y. Yu, H. Sun, P. K.-H. Tam, J.-F. Chiu, C.-M. Che, JBIC J. Biol. Inorg. Chem. 2007, 12 (4), 527-534. https://doi.org/10.1007/s00775-007-0208-z

9. A. Pallaoro, G. B. Braun, M. Moskovits, Proc. Natl. Acad. Sci. 2011, 108 (40), 16559-16564. https://doi.org/10.1073/pnas.1109490108

10. C. B. Murray, S. Sun, H. Doyle, T. Betley, Mrs Bull. 2001, 26 (12), 985-991. https://doi.org/10.1557/mrs2001.254

11. Cb. Murray, D. J. Norris, M. G. Bawendi, J. Am. Chem. Soc. 1993, 115 (19), 8706-8715. https://doi.org/10.1021/ja00072a025

12. X. Y. Chen, C. Ma, Z. J. Zhang, X. X. Li, Microporous Mesoporous Mater. 2009, 123 (1-3), 202-208. https://doi.org/10.1016/j.micromeso.2009.04.002

13. T. Nakamura, K. Takasaki, A. Ito, S. Sato, Appl. Surf. Sci. 2009, 255 (24), 9630-9633. https://doi.org/10.1016/j.apsusc.2009.04.092

14. T. Nakamura, Y. Mochidzuki, S. Sato, J. Mater. Res. 2008, 23 (04), 968-974. https://doi.org/10.1557/jmr.2008.0115

15. T. Nakamura, H. Magara, Y. Herbani, S. Sato, The proceeding of the 7th International Symposium on Atomic Level Characterization for New Materials and Devices, Maui-Hawai, USA, 2009, pp 507-510.

16. S. Sun, C. B. Murray, D. Weller, L. Folks, A. Moser, Science, 2000, 287, 1989-1992. https://doi.org/10.1126/science.287.5460.1989

17. A.-T. Le, P. D. Tam, P. T. Huy, T. Q. Huy, N. Van Hieu, A.A. Kudrinskiy, Y.A. Krutyakov, Mater. Sci. Eng. C 2010, 30 (6), 910-916. https://doi.org/10.1016/j.msec.2010.04.009

18. D. P. Brunco, J. A. Kittl, C. E. Otis, P. M. Goodwin, M. O. Thompson, M. J. Aziz, Rev. Sci. Instrum. 1993, 64 (9), 2615- 2623. https://doi.org/10.1063/1.1143879

19. D. Kokkinos, P. Gailly, M.P. Georges, G. Tzeremes, P. Rochus, K. Fleury-Frenette, Appl. Opt. 2015, 54 (36), 10579-10585. https://doi.org/10.1364/AO.54.010579

20. K. S. Birdi, Handbook of Surface and Colloid Chemistry, CRC Press, Boca Raton, 2015.

21. C. F. Bohren, D. R. Huffman, Absorption and Scattering of Light by Small Particles; John Wiley \& Sons, 2008.

22. M. Kerker, The Scattering of Light and Other Electromagnetic Radiations, Academic Press, New York, 1969. 
23. S. Link, M. A. El-Sayed, Int. Rev. Phys. Chem. 2000, 19 (3), 409-453. https://doi.org/10.1080/01442350050034180
24. J. Zheng, P. R. Nicovich, R. M. Dickson, Annu. Rev. Phys. Chem. 2007, 58, 409.

https://doi.org/10.1146/annurev.physchem.58.032806.104546

\section{Povzetek}

$\mathrm{Z}$ obsevanjem raztopine $\mathrm{AgNO}_{3}$ (amoniak-alkohol) s fokusiranim laserskim žarkom (Nd:YAG laser) smo sintetizirali nanodelce srebra. Karakterizirali smo jih z naslednjimi metodami: vrstično elektronsko mikroskopijo (SEM) in energijsko disperzijsko spektroskopijo (EDX), tehniko dinamičnega sipanja svetlobe, absorpcijsko in luminiscenčno spektroskopijo. Povprečna velikost sintetiziranih nanodelcev, ki je od 25 do $100 \mathrm{~nm}$, dokazuje linearno odvisnost molarne koncentracije uporabljene raztopine. Prikazane so optične in luminiscenčne lastnosti dobljenih nanodelcev srebra. 